\title{
Interactive comment on "Surf3DNet1.0: A deep learning model for regional-scale 3D subsurface structure mapping" by Zhenjiao Jiang et al.
}

Anonymous Referee \#2

Received and published: 8 December 2020

Dear authors: Please do not be too discouraged by this less than positive review, since it may be due to some major misunderstandings that I outline below. I hope they are indeed misunderstandings and you can revise to resubmit, as I suspect your DL algorithm will ultimately be worthy of publication.

My review of this paper is not favorable mainly because, despite repeated readings of it, I am unable to identify the specific research problem that the authors are seeking to solve, and because the case study used to demonstrate their method appears to be trivial in the context of subsurface characterization. Although it is possible my reactions stem from major misunderstanding of the descriptions of the objectives, methods and results, I have spent decades of my career mapping and modeling paleochannels, including application of AEM and other geophysical methods, yet I am unable to rec-

Printer-friendly version

Discussion paper 
oncile the separation between what the authors are writing and what I would consider to be understandable or obvious contributions.

My trouble with the objectives and problem definition can be best illustrated by first considering the geologic system the authors seek to better map in 3D. 'Paleochannels' can take on a number of different meanings depending on the geologic setting, but from what I can decipher from the introduction, methods and Fig. 2, by 'paleochannels' the authors are referring to incised valley fill deposits like those depicted in Fig. 2b, where the channels are bounded not by adjacent fluvial facies, but by granite. Setting aside for the moment that this looks more like a basin and range style of geologic structure than a paleochannel, based on the vague descriptions in the paper, I can only construe that the flattest portions of the DEM shown in Fig. 2c represent the Quaternary alluvial bottomlands representative of the top of the apparent paleochannels (i.e., top of sed facies in Fig. 2b). If that is true, the reader's reaction is inevitably: "Why is this even considered a challenging problem? From the topography it is already obvious where these so-called channel deposits locate."

Summarizing the case study, it appears that the DEM already nicely identifies locations of the paleochannels, which apparently have been further characterized using AEM, presumably to better identify their depths or depth to bedrock perhaps. This raises the question of what is the problem the authors are attempting to address? If the problem is to better identify $x$-y locations of the so-called paleochannels, that would appear moot because the DEM already shows them, which also raises the question of why you need $\mathrm{DL}$. If the problem is to better identify paleochannel or incised valley-fill depths, that has apparently already been done with AEM; and furthermore, if the purpose is to use the $\mathrm{DL}$ algorithm to map the paleochannels depths so that AEM would not be needed, that also does not appear to make sense because the authors have not established a relationship between the DEM flatness metric and paleochannel depths.

It is possible that if the authors can be more specific about the geology of these 'paleochannel' features that they are trying to map and about what specifically they are

Printer-friendly version

Discussion paper
Interactive comment 
trying to accomplish through the application of their ML methods, the above problems would be cleared up. As written, however, the manuscript lacks sufficient definition of the problem, description of their objectives, and description of how their research satisfies those objectives.

I am attaching an annotated PDF file showing some edits and comments in the manuscript. This is best viewed as two-facing pages, where the left page shows the manuscript page with index numbers, and the right page shows the indexed comments and edits.

Please also note the supplement to this comment:

https://gmd.copernicus.org/preprints/gmd-2020-106/gmd-2020-106-RC2-

supplement.pdf

Interactive comment on Geosci. Model Dev. Discuss., https://doi.org/10.5194/gmd-2020-106, 2020. 